\title{
The Transition Process for Adolescents with Learning Disabilities: Perspectives of Five Families
}

\author{
Stephanie Fullarton, Cheryll A. Duquette \\ University of Ottawa
}

\begin{abstract}
This qualitative study examines, from the perspective of the families, the transition process to employment or postsecondary education for adolescents with learning disabilities (LDs) and the interplay of the roles of parents, students with LDs, and teachers. Using a case study design, series of three in-depth interviews were conducted with five individuals with LDs and with their parents. Data were analyzed inductively. The findings indicate that the families all had informal transition plans; formal transition plans were not written. For four of the families, the transition process was successful and occurred in two phases spanning the elementary and secondary school years. In the first phase parents controlled the transition process, and during the second phase they transferred this responsibility to their children with LDs. Parents' high expectations and advocacy; students' hard work, self-determination and self-advocacy; and teachers' mentoring and support also contributed to the achievement of transition goals. Throughout the process parents, adolescents with LDs, and teachers worked collaboratively. In the fifth case, only the factor of parental advocacy was in place, and it was insufficient to bring about a successful transition for the adolescent with LDs.
\end{abstract}

Transition planning has become mandatory across Canada and the United States to help students with disabilities and their parents plan for employment and postsecondary goals (Benz, Lindstrom \& Yovanoff, 2000; Blackorby \& Wagner, 1996). In Ontario, transition planning in schools is intended to serve students with disabilities by taking their interests, strengths, and needs into consideration when developing a transition plan (Ministry of 
Education, 2002). Educators in partnership with students with disabilities, their parents, and the community (when appropriate) are meant to meet annually to discuss post-school goals and the course work and skills required for employment or postsecondary education. The literature is thin on the roles teachers, students with disabilities, and parents play and on how they interact to produce a successful transition to employment or postsecondary education. The purpose of this research is to examine the transition process from the perspectives of students with learning disabilities (LDs) and of their parents, in order to understand the interplay between their involvement and the actions of the school.

\section{Roles in the Transition Process}

Teachers. When planning for employment, adolescents with LDs require a plan that is specific to their learning needs (Mellard \& Johnson, 2007). Several studies have reported the importance of school-to-work transition programs facilitated by the school for meeting post-school employment goals (Baer et al., 2003). Transition research also points to the importance of connecting students with disabilities, such as LDs, to vocational education and related work experience during the high school years (Trainor, 2008). Teachers can facilitate transition plans focussed on employment goals by offering students with LDs career-related activities, such as vocational assessments, co-operative education placements, and mock job interviews (Benz et al., 2000). Paid and voluntary work experiences during high school and vocational and employment social skills training also facilitate successful transition to employment (Benz et al., 2000; Kohler, 1993; Mellard \& Lancaster, 2003). As well, teachers can serve in the critical role of mentors who guide students with LDs through the career exploration and decision-making experience and help them build connections in the workplace (Izzo \& Lamb, 2002).

Another post-school option for students with LDs is postsecondary education. However, the literature on the role of teachers in such a transition process of students with LDs is less developed than for employment. This reduced attention by researchers may be related to the proportion of students with LDs whose transition goal is further studies. Only about one third of students with LDs enrol in postsecondary programs (Wagner, Newman, Cameto, Levine, \& Garza, 2006), and only 19.5\% graduate within 5 years of high school (Murray, Goldstein, Nourse, \& Edgar, 2000). Factors contributing to low postsecondary graduation rates among students with LDs include a poor fit between the strengths of the student and the demands of the program, inadequate academic preparation, lack of services at the institution, less-than-supportive faculty and administration, and personal situations (Kurth \& Mellard, 2006; Murray, Flannery, \& Wren, 2008). Additionally, due to stigma about their LDs, some students are reluctant to ask for accommodations and may attempt their courses without them, resulting in poor academic outcomes (Briel \& Getzel, 2001; Fullarton, 2006; Sowers \& Smith, 2003). However, transition planning that includes self-determination and self-advocacy training provided by the school can help students with LDs adjust successfully to a postsecondary program while encouraging student ownership of the process (Durlak, Rose, \& Bursuck, 1994; Phillips, 2001). In sum, teachers can play a part in helping adolescents achieve their employment or postsecondary education transition goals. Generally, their role is either (a) mentoring students and helping them acquire skills and competences or (b) providing support for students (Repetto, Webb, Neubert, \& Currans, 2006). 
Students with LDs. According to Pocock et al. (2002), self-determination is a psychological construct related to knowledge about one's strengths and limitations that is necessary to foster a belief in oneself as capable, effective, and successful. For individuals with disabilities, it involves awareness of specific support services and accommodations that may be of assistance at the institution (Field, Sarver, \& Shaw, 2003) and the extent to which a person assumes responsibility for his or her own goals, accomplishments, and setbacks (Ward, 1988). Knowledge and acceptance of disabilities are important elements of self-determination (Beale, 2005; Durlak et al., 1994), and individuals need to place them in perspective and reframe them as a positive element in their lives (Higgins, Raskind, Goldberg, \& Herman, 2002). Self-determination is considered essential for adolescents with LDs to achieve successful transition to employment and postsecondary education (Durlak et al., 1994; Merchant \& Gajar, 1997; Ryan \& Deci, 2000; Zhang, 2001). Typically it is regarded as an individual characteristic, and less attention has been paid to the factors within the environment that interact with the development of self-determination (Abery \& Stancliffe, 1996; Trainor, 2008).

Self-advocacy is a component of self-determination and is defined as the ability to speak on one's behalf and represent personal needs and interests (Kotzer \& Margalit, 2007). To both employment and postsecondary education, it also involves identifying one's learning strengths and needs, interests, knowledge of individual rights, and the ability to communicate learning needs and required accommodations clearly (Durlak, et al., 1994; Merchant \& Gajar, 1997; Walker \& Test, 2011). Mishna, Muskrat, Farnia, and Weiner (2011) contended that self-advocacy is especially important for students with LDs whose post-school goals include further studies at university or college. However, only a few adolescents with LDs acquire self-advocacy skills without instruction (Michaels, 1994), often because they rely on parents and teachers to advocate and make choices for them (Mishna et al., 2011; Zhang, 2001), or they have been too focused on their learning weaknesses (Vogel \& Adelman, 1993). Self-advocacy training offered in schools usually consists of providing information and teaching skills through direct instruction. It is followed with active participation in individual education plan (IEP) meetings (Van Reusen \& Bos, 1994) and in sharing information about strengths, preferences, interests, needs; identifying postsecondary goals; and requesting accommodations from teachers (Durlak, et al., 1994; Prater, Redman, Anderson, \& Gibb, 2014).

Parents. Parents may also play an important role in the transition of children with LDs from high school to employment or postsecondary education. Several studies show that high expectations in the home lead to high achievement and goal setting by the adolescent with LDs (Baer, et al., 2003; Reis, Neu, \& McGuire, 1997; Wagner, Newman, Cameto, Garza, \& Levine, 2005). Parents who have high expectations for their adolescents with LDs influence their attitudes toward school, provide financial and emotional support, and advocate for their children at school (Wagner, et al., 2005).

For students with LDs whose plans are directed toward employment, Lindstrom et al. (2007) reported that family process variables worked in combination to form three patterns of family interaction: advocates, protectors, and removed. Parents who were advocates had high levels of involvement with their children and provided support, advocacy, and intentional career-related planning. They also allowed their adolescents with LDs to make decisions and encouraged learning from mistakes. Although the 
parents in the protectors group were also involved in their children's daily activities, their participation was characterized by high levels of control and structure. They held vague or low expectations for their children and did not encourage independent decision making or job exploration activities. Parents who were removed were less involved and supportive than the other two groups, and many of the family relationships were negative or unstable. However, several of the youth in this group had high school transition specialists who were available to offer advocacy, support, and intentional career-related activities. These teachers more or less assumed the role of the parent in the students' transition process. The findings of that study, therefore, point to the importance of the role of parents in the transition from high school to employment (Lindstrom, Doren, Metheny, Johnson, \& Zane, 2007).

Parents may also expect their child to set their sights on postsecondary studies; they may do so because they pursued higher education themselves and impart that value to their children with LDs (Newman, Wagner, Cameto, \& Knokey, 2009). Moreover, these parents facilitate the process by helping with applications, planning an educational program, and taking campus tours with their adolescents (Newman, et al., 2009). Parental advocacy has also been related to positive transitions to postsecondary education (Fullarton, 2006). In a Canadian study, parents who advocated on behalf of their child with LDs in school modeled advocacy skills that were implemented during their postsecondary studies by their children. These skills were vital to obtaining accommodations and services that were necessary for successful course completion (Fullarton, 2006). However, the absence of parental advocacy is not necessarily linked to poor postsecondary results. In research conducted by Litner, Mann-Feder, and Guérard (2005) parental advocacy was not related to graduation from a postsecondary institution by young adults with LDs. The participants in that study compensated for the lack of family support by developing resilience and finding role models who provided support (Litner et al., 2005).

As shown above, teachers, students with LDs, and parents can influence the transition process for students with LDs. While most studies examined outcomes of transition, the literature on the process of transitioning from high school to employment or postsecondary studies and the interaction of the three stakeholders is not well developed. The purpose of this research was to examine the roles of parents, adolescents with LDs, and teachers during the process of transitioning from high school to understand the nature of their collaboration from the perspectives of the students with LDs and their parents.

\section{Methodology}

A qualitative approach was used to understand the experiences of adolescents with LDs and their parents during the transition process, and a case study design was selected to describe the stories of transition experiences of five families (Creswell, 2009). The research reported here is a part of a large study conducted in eastern Ontario involving case studies with multiple participants in each case. 


\section{Case Study Design}

To understand the perspectives of the five individuals with LDs and their parents, a qualitative approach was selected (Creswell, 2009). A case study design was used to gain an in-depth understanding of the contexts and the meaning for those involved (Merriam, 1998). The voices of the participants within each case study contributed to the understanding of their roles and responsibilities during the transition process. This research took the form of multiple case studies (Stake, 1995) whereby each family's experience was described and a cross-case analysis was conducted to suggest themes about the interaction of the roles of students, parents, and teachers during transitions. Merriam (1998) contended that the inclusion of many cases is a common strategy for enhancing the transferability of the findings.

\section{Participants}

Participants in this research were recruited through a notice placed on the websites of two LD associations and on the boards of special services departments at local colleges and universities. Five families volunteered to participate in the research. It was the mother in each family who managed the majority of the school-related activities for her children, and she had the most information to share about the transition process. In three cases, the fathers also participated, but in two families relations were strained and either the mother or adolescent with LDs did not want him involved. In all but one family the adolescents with LDs had achieved their transition goals or were working toward them. For the most part, the participants shared their stories of how they achieved a successful transition. Pseudonyms were selected by the first author to protect the identity of all the participants, except that Darth chose his own pseudonym. Information on each family is provided in Table 1.

\section{Data Collection}

Two instruments were used to gather data from each of the five families: a questionnaire and interview protocols. Demographic data were collected using a questionnaire before each family was interviewed. It served to provide background information and gave the participants a sense of the types of questions that would be asked. Seidman's (2006) three-interview series was used in this study; two families chose to be interviewed in person, and three families were interviewed by telephone. The first interview focused on the context of the experience, the second one gave the participants the chance to reconstruct the details of their experience, and the third interview provided opportunities for reflection on the meaning of the experience (Seidman, 2006). During the first interview, participants were asked questions about the process of obtaining a diagnosis, early school experiences, social experiences, and family relationships. The data from this interview were used to construct a timeline of events. In the second interview present educational experiences, social experiences, and relationships with family members were explored. The questions in the third interview were framed in such a way to encourage reflection on the past interviews, for example, "Given what you said about your career goals, what steps will you take during the transition process to reach them?" While the structure of the interviews and intent of each question was the same for 
all participants, the wording of the questions varied depending on their role (adolescent or parent) and on the information they had previously provided (e.g., goal of employment or goal of postsecondary studies).

The adolescents with LDs and the parents in this study participated in three 90minute semi-structured interviews as described above. Parents and adolescents with LDs were interviewed separately and the interviews in the series were conducted at least a week apart to allow for reflection. The interviews were digitally recorded, and the transcripts were sent to the participants so that they could ensure that the ideas were expressed to their satisfaction.

\section{Table 1}

The Participants

\begin{tabular}{|c|c|c|}
\hline Family & Categories & Family Description \\
\hline Heron family & $\begin{array}{l}\text { Adolescent with LDs } \\
\text { Diagnosis } \\
\text { Parents } \\
\text { Transition goal }\end{array}$ & $\begin{array}{l}\text { Alice, age } 17 \text { years, Grade } 11 \\
\text { LDs, CAPD* } \\
\text { Audrey and Oliver } \\
\text { Not identified }\end{array}$ \\
\hline Magpie family & $\begin{array}{l}\text { Adolescent with LDs } \\
\text { Diagnosis } \\
\text { Parents } \\
\text { Transition goal }\end{array}$ & $\begin{array}{l}\text { Vincent, age } 22 \text { years, apprenticeship } \\
\text { LDs including dyslexia } \\
\text { Grace and Garrett } \\
\text { Employment (diesel mechanic) }\end{array}$ \\
\hline Sparrow family & $\begin{array}{l}\text { Adolescent with LDs } \\
\text { Diagnosis } \\
\text { Parent } \\
\text { Transition goal }\end{array}$ & $\begin{array}{l}\text { Darth, age } 16 \text { years, Grade } 11 \\
\text { Non-verbal LDs, giftedness } \\
\text { Donna (father did not participate) } \\
\text { University (film studies) }\end{array}$ \\
\hline Robin family & $\begin{array}{l}\text { Adolescent with LDs } \\
\text { Diagnosis } \\
\text { Parents } \\
\text { Transition goal }\end{array}$ & $\begin{array}{l}\text { Laura, age } 19 \text { years, first-year university } \\
\text { Non-verbal LDs, giftedness } \\
\text { Fiona and Tom } \\
\text { University (math and education) }\end{array}$ \\
\hline Cardinal family & $\begin{array}{l}\text { Adolescent with LDs } \\
\text { Diagnosis } \\
\text { Parents } \\
\text { Transition goal }\end{array}$ & $\begin{array}{l}\text { Mary, age } 17 \text { years, Grade } 12 \\
\text { Mental health problems, LDs } \\
\text { Eva and Jim (Jim did not participate) } \\
\text { University (business and law) }\end{array}$ \\
\hline
\end{tabular}

*central auditory processing disorder

\section{Data Analysis}

Data in this qualitative study were analyzed inductively and by hand to increase the researchers' engagement with the data (Charmaz, 2000). Specifically, the transcripts were read repeatedly and notes were made in the margins. Next, chunks of data related to the actions of parents, students with LDs, and teachers were highlighted, coded, and categorized (Miles \& Huberman, 1994). Then, profiles tracing the transition process for each family 
were created. Using the profiles, the researchers conducted a cross-case analysis separately, and agreement was reached on the themes that emerged related to the roles of parents, individuals with LDs, and teachers. Two criteria of trustworthiness were used to ensure that the findings were worthy of note and transferrable to other individuals (Lincoln \& Guba, 1985). Credibility refers to the fit between the participants' intended meaning and the researcher's reflection of it (Mertens, 2005). Member checks ensured that the participants approved the transcripts of their interviews. Transferability refers to the ability of readers to transfer the findings to other situations, cases, or populations (Creswell, 2009). In this research, the multiple case studies in which the primary informants were interviewed three times provided a rich description of the participants' experiences.

\section{Findings}

\section{Case Studies}

Heron family. Alice, a 17-year old in Grade 11 and her mother, Audrey, each participated in three telephone interviews, while Oliver, Alice's father, was interviewed once. Alice was diagnosed at the age of 8 years with LDs that included severe deficits in communication (a speech impediment and central auditory processing disorder). Audrey was her primary caregiver and advocate, a job she found "exhausting and frustrating." Oliver provided emotional and financial support. Neither of the parents attended a postsecondary institution, and Oliver was a manual labourer who had worked at many different jobs. Audrey stayed at home to care for her children for several years and recently gained employment doing secretarial work through training funded by the Ontario Disability Support Program (ODSP). Alice had two older sisters: Jane, 20 years, and Beth, 18 years. Both girls were attending college programs, and Alice also expressed an interest in college.

Alice did not participate in IEP meetings and did not take advantage of the services offered at her high school or use a computer for assignments due to feelings of embarrassment. Audrey was concerned that the teachers were not providing the accommodations written on the IEP. She explained that the teachers wanted Alice to ask for them, but she did not: "I go and I advocate for her, but they don't want to hear from me-they want her to tell them what she needs." Moreover, her mother revealed that Alice sat quietly in class and brought the work home for her to complete.

She is supposed to have modified work but they seem to give her all of the same stuff they give the other kids. So what I have been doing over the years is she just brings me the work that she gets done and I finish the stuff and hand it in for her.

Alice had therefore developed learned helplessness in regard to her schooling. At the time of the interviews Alice was taking essential level courses (basic content) that did not prepare her for postsecondary studies, and Audrey complained:

[The teachers] didn't inform me that her program wouldn't allow her to go to college ... If the high schools don't tell you what you need to know to get your child into the right program in order to go to college, then your child won't be going.

Alice had worked in a pumpkin patch part-time for two or three weeks, then was let go. At school, she was socially isolated from her peers. 
Audrey's goal for her youngest daughter was graduation. She spoke frankly when she said, "My focus for right now is to see her graduate. We have some ideas for her future, but for right now I have to focus on getting her a diploma." Following graduation Audrey hoped that Alice would be eligible for ODSP support:

If they will give her an allowance, then I want to look into some sort of art class like pottery or something like that that she can take, and then maybe I would help her set up a studio and I would help her sell her art.

Hence, the usual transitional goals of employment or postsecondary studies at college or university had not been identified and were not being pursued. The plan to receive government funds to turn a newly developed hobby into a viable business seemed unrealistic because this type of support is designed for people possessing marketable skills who need help setting up their business (e.g., writing a business plan or training in money management or marketing; Ontario Ministry of Community and Social Services, 2012). At the time of the interviews Alice had not taken an art class and did not have a marketable skill. Moreover, Alice did not appear to be involved in the planning or fully engaged in the goal of high school graduation, as she permitted her mother to do some of the homework. The learned helplessness extended into Alice's personal life, as Audrey commented that she still ran her daughter's bath water "because she can't remember which tap is hot and which is cold." Audrey and Oliver did not expect Alice to achieve independence and accepted that as an adult, she would live with them.

Magpie family. Grace and her 22-year-old son, Vincent, each participated in three separate face-to-face interviews, while his father, Garrett, was interviewed once. The Magpie family consisted of five members: Vincent, the adolescent diagnosed with LDs, mother Grace, father Garrett, and two younger siblings, (Gwyneth, 20 years, and Alistair, 18 years). Both parents completed high school, but neither had studied at the postsecondary level. Garrett was a truck driver and Grace worked in a factory. Vincent was diagnosed with LDs in the primary grades, and Grace reflected that having the diagnosis was "a relief, actually." Grace advocated on his behalf during elementary school and helped him with assignments at home. Vincent was aware of his learning strengths and clearly described how he learned, the type of instruction he preferred (oral presentation with demonstration), and the accommodations he required. He attended all of his IEP meetings and requested accommodations only when he needed them. As Vincent progressed in high school, he reported, "The farther I got, the less help I asked for"; and he noted that accommodations were not required at all in his shop or technology courses. He had a small group of close friends and participated in extracurricular sports.

Grace and Garrett selected the transition goal of employment from an early age, and they emphasized the importance of work and accepting responsibility. Throughout high school Vincent worked on a nearby farm for 20 to 30 hours a week before and after school. He did well in shop or technical courses, and his parents encouraged him to take a wide variety of these courses during high school so that he could make an "informed decision" on a career. Vincent also made a connection with one of his technical course teachers. This teacher took it upon himself to find a co-operative education placement for Vincent, which led to an offer of a paid job on the weekends. He also met with Vincent and his parents to discuss career goals and helped them make plans for his transition. 
With the support of a teacher, Vincent was the first person in their family to be in an apprenticeship program and was training to become a diesel mechanic.

Sparrow family. Donna was a single parent raising Darth, an only child aged 16 years. She held a master's degree and did consulting work for the federal government. The face-to-face interviews for her and her son were arranged by Donna, and she requested that Darth's father not be contacted. When Darth was in the primary grades, Donna was concerned about her son's academic progress and mental health. She decided to have him assessed privately, and in Grade 4 Darth received a dual diagnosis: giftedness and non-verbal LDs.

In elementary school, Darth experienced many academic challenges. Donna attended the IEP meetings and advocated strongly for academic accommodations. Darth described how he was bullied mercilessly in elementary school and stated, "I was one of the most unpopular kids; even the losers picked on me." When Darth was in Grade 6, Donna felt that her son needed to change peer groups. She researched the services offered in the local board of education and decided that an alternative school for Grades 7 and 8 would work for her son. During an interview she explained that at this school the teachers provided accommodations for her son (extra time for tests and a quiet location to write them) and used tiered instruction to address various ability levels. It was at this point that Darth began using a computer for his written work, and he commented, "By Grade 8, writing was one of my strengths." He also received paraprofessional support to help him stay organized, and he found social acceptance within a small group of friends. Darth was interested in music and claimed to know at age 2 that he wanted be a filmmaker. With this goal in mind, he worked hard to be accepted into an arts-based high school, where being "different" was valued. Throughout his childhood and adolescent years, Donna supported his interests by enrolling him in extracurricular activities, such as film studies camp and other arts-based activities. His mother insisted that his transition goal be university, and Darth investigated film studies programs offered at various universities. He took the initiative to work with a guidance counsellor to ensure that he had taken all the prerequisite courses and filled out the application forms. During his high school years, Donna began transferring the advocacy role to her son. At the time of the interviews, she was giving advice and arranging school visits and financial aid. Darth was assuming responsibility for researching the programs, making decisions, self-advocating, aligning himself with supportive people, monitoring his progress, and working toward his goals. He was becoming fully aware of his interests, academic strengths, and needs and had learned through hard work that he was capable of achieving his goals. Darth viewed his LDs as an important reason for his creativity and reflected, "I think creativity and LD go hand in hand. Creative people have to be kind of weird and I wouldn't have it any other way."

Robin family. Three members of this family participated in telephone interviews. Laura was 19 and in her first year at university. She and her mother, Fiona, were interviewed individually on three separate occasions; and Tom, Laura's father, was interviewed once. Laura was born in Ukraine and immigrated to Canada at age 5, along with her parents and younger sister. Both parents earned master's degrees and have professional careers. As an immigrant, Laura described herself as an outsider because she did not speak English when she first arrived. She felt that no one wanted to talk to her 
because "I was the weird kid." However, Laura did well academically, and by Grade 4 she had entered the French immersion program and became fluent in a fourth language. In Grade 10 she experienced trouble concentrating, slow processing speed, and an inability to follow teachers' instructions. She procrastinated on assignments, became very anxious, developed an eating disorder, and was hospitalized for a brief period. During her hospitalization, she received psychological counselling and was assessed for LDs. In Grade 11, she was diagnosed with giftedness and non-verbal LDs. While Laura accepted this diagnosis, her mother expressed embarrassment and surprise that someone who was gifted could also have learning problems.

I didn't want to hear that my kid had an LD. I am still embarrassed to talk about it. I never talk about it with other people, only with family. I do like to tell other people about her being gifted, but LD - that makes me feel that she is not normal.

The resource teacher at Laura's high school advocated for accommodations for her so that she could have extra time to write exams and submit assignments. Once the teachers understood her academic and emotional difficulties, they were willing to provide the accommodations Laura needed to pass her courses. The learning strategies course taught in the resource room also provided her with time-management and organizational skills. Laura attended the IEP meetings with her parents and worked very hard on her courses. Tom and Fiona expressed at an early age that they expected Laura to study at a university, and she wanted to be a math teacher. Her parents monitored her grades to ensure that they were sufficiently high to be accepted into a university program. She was very determined to reach her career goal as a math teacher and had a strong work ethic. During the summers in high school she held a part-time job, but found it too stressful to continue working during the school year.

Cardinal family. The Cardinal family consisted of Mary, a 17-year-old with LDs; her parents, Eva and Jim; and her older brother, Robert. Eva and Mary participated in telephone interviews and Mary requested that her father not be involved in this study. Eva, a university graduate, was a teacher. Her father did not complete high school and worked as a labourer for a railway company. Eva stated that she first suspected LDs in Grade 1 when her daughter struggled with writing and spelling. By Grade 5 Laura was experiencing problems in math, was being ridiculed by peers, and was having anxiety attacks. However, her academic performance was not sufficiently low to qualify her for assessment by one of the board's psychologists. In Grade 6 Mary began withdrawing socially and attempted suicide. Two years later, she was diagnosed with depression and anxiety disorder and received accommodations: extra time to write tests and for assignments, no penalties for spelling, and a quiet place to work when needed. In elementary school, Eva advocated for a psycho-educational assessment for her daughter, but was denied. As it turned out, the accommodations for anxiety were sufficient until the end of elementary school.

Mary's academic progress was monitored by the school in Grade 9, and she was referred to a board psychologist the following year for an assessment. Eva stated that they were relieved when they finally received the diagnosis of LDs and an expanded list of accommodations for her daughter. She then purchased a laptop and the word predictive and word recognition software for her daughter because the school refused to do so. The 
resource room teacher helped her with her visual memory and she was permitted to use a word bank when writing exams. The diagnosis of LDs and the academic success due to the accommodations confirmed Mary's belief that she is intellectually competent but "working at a disadvantage." Mary was very aware of her learning strengths and weaknesses and was comfortable discussing accommodations with her teachers.

Eva also provided Mary with emotional support, helped her improve her physical appearance (a new hair style and clothing), and forced her to join sports teams to make friends. As she gained self-confidence, she developed a group of friends who set their sights on university and shared her value of working hard to achieve high marks. Mary's parents expressed the expectation that she go to university, and she decided to complete a degree in business then apply to law school. Mary researched the programs and entrance requirements of various universities to ensure that she was informed. On one occasion she had to remind a guidance counsellor who urged her to take the college-level math and English courses that she needed advanced level high school courses for admission into a university program. Mary was driven to succeed and reflected, "Maybe I would not have been as ambitious as I am if I didn't struggle so much when I was younger. I think it motivated me even more than my mother's expectations of me." With hard work, selfadvocacy to obtain accommodations, and the support of her mother, Mary was working toward her postsecondary goals.

\section{Discussion}

Several themes emerged from the data; they related to the roles of parents, students with LDs, and teachers during the transition process from high school (see Table 2).

Table 2

Themes

\begin{tabular}{ll}
\hline Theme & Description \\
\hline Role of parents & $\begin{array}{l}\text { - Express expectations: employment or postsecondary studies } \\
\text { - Model advocacy, transfer responsibility for the transition process } \\
\text { during high school }\end{array}$ \\
Role of adolescents & $\begin{array}{l}\text { - Select a career or postsecondary program } \\
\text { with LDs }\end{array}$ \\
& - Develop self-advocacy and self-determinations skills \\
& - Kevelop a mentoring or supportive relationship with a teacher \\
Role of teachers & - Provide mentoring or support for the adolescent \\
& - Collaborate with the adolescent and parents
\end{tabular}

\section{Roles of Parents}

The parents did not recall working with teachers to prepare a formal transition plan for their children. This finding is not surprising, as other research shows uncertainty on the part of special education teachers about their role in the transition planning process (Nichols, Paul, Vanderbossche, Yaworski \& Ziraldo, 2003) and a lack of involvement by 
guidance counsellors (Milsom, 2002). In this study, none of the parents expressed concern or regret that the school had not taken the lead in preparing a formal transition plan. These parents were involved in their children's education and took the initiative to develop informal transition plans with their adolescents.

Expectations. All of the parents expressed post-school goals that were similar to their own experiences (Fullarton, 2006; Newman, et al., 2009). In all but one family, the parents had typical post-school goals (i.e., employment or postsecondary studies and eventually independent living), and they stressed the values of responsibility and hard work. They also supported their children in non-school activities that led to the development of work skills (e.g., part-time employment) or an interest (e.g., film studies camp). Only Alice's parents stated that they thought their daughter could apply to a social services program upon completion of high school, and they did not expect her to develop work skills by having a part-time job, either during the school year or in the summer. Hence, unlike the other parents, they retained control over her life and did not encourage independent decision making or hard work at school or in a part-time job, which hindered the transition process into adulthood.

Advocacy. The mothers in all five families took on the primary role of educational advocate for their son or daughter. This finding has been reported in other research on educational advocacy (Duquette, Stodel, Fullarton, \& Hagglund, 2012; Traustadottir, 1991). In four families advocacy began in elementary school when the children were identified as having LDs and/or mental health problems. The mothers attended the IEP meetings, made the case for accommodations for their children, and monitored their progress. Darth's mother, Donna, realized that teachers who understood LDs could make a difference for her son, and she took on the additional role of investigating alternative schools in her district. In Grade 7 she advocated for Darth's admission to the school, and the instructional styles of his teachers and the programs were a better match for him. However, the mothers' advocacy efforts did not always produce the desired results. For example, Eva, a teacher in her daughter's school, recognized in Grade 1 that Mary likely had LDs, but even as an insider, Eva was unsuccessful in her request to have her daughter assessed. It wasn't until Mary had a breakdown and a mental health diagnosis in Grade 6 that an IEP and accommodations were provided. Unlike the other families, advocacy was not required for Laura in elementary school, as she was in the French immersion program and considered to be extremely intelligent.

During the high school years, Donna, Grace, and Eva reduced the amount of advocacy they undertook and transferred greater responsibility to their children, a practice recommended in the transition literature (Phillips, 2001). They still signed the IEP documents to ensure that the accommodations were listed, but they expected their children with LDs to request them. Fiona, Laura's mother, attended the first IEP meeting but played a minimal role, possibly because her daughter was not diagnosed until Grade 11 and she found it confusing that an individual could have a dual diagnosis of intellectual giftedness and LDs.

In contrast, Audrey continued to accept all of the responsibility for educational advocacy. She ensured that specific accommodations were written in the IEP and expected the teachers to modify the curriculum, take the initiative in asking Alice if she 
understood the work, and provide accommodations. However, the teachers felt that Alice should take responsibility for requesting accommodations (Zhang, Katsiyannis, Zhang, 2002), asking for clarification, and making use of the accommodations and equipment she was given. They likely did not modify the curriculum because her courses were at the lowest level of difficulty. This situation frustrated Audrey, who felt that the teachers should simply accept that Alice was needy and provide assistance and accommodations. Her statements appeared to reflect a belief that Alice was incapable of completing the work on her own and should not be expected to accept much responsibility for her academic outcomes.

The findings on the roles of parents provide some support for Lindstrom et al.'s (2007) categorizations of parental roles during the transition to employment. Grace and Gareth could be described as "advocates" (Lindstrom, et al., 2007), as they encouraged Vincent to explore possible career options through high school shop and technical courses and co-operative education placements, and they promoted self-determination and allowed independence. These parents also provided support and engaged in advocacy and intentional career-related planning activities. Moreover, during the high school years they had the assistance of a teacher who mentored Vincent and provided opportunities for him. In a previous study, Blustein et al. (2002) noted that parents with less education and fewer economic resources had difficulty imparting knowledge about career pathways to their children. In this research, Grace and Gareth held blue collar jobs, and it was the teacher who provided this type of career information to Vincent.

Alice's parents' actions appear to fit the "protector" category (Lindstrom et al., 2007). While involved in Alice's education, Audrey and Oliver had low aspirations for their daughter and had not undertaken intentional planning for employment. The most pressing goal was high school completion, and later social assistance would be investigated to support the vague goals of setting up a pottery studio and selling her art. Unlike Vincent's parents, Audrey and Oliver appeared to have low expectations for transition to adult life, and neither Alice's parents nor a teacher engaged in career planning with her.

Lindstrom et al. (2007) reported that when their parents were "removed" or not engaged in the transition process, teachers engaged in goal setting and career exploration activities with students with LDs transitioning to employment. However, in this study, Vincent's parents were active participants who involved their son in the process, and the teacher was an additional collaborator that guided the process and afforded Vincent opportunities he might not otherwise have had. In contrast to Vincent's mother and father, Alice's parents established vague post-school goals and did not expect their daughter to live independently. As well, Alice did not have a teacher who mentored her or provided support, and relations between the parents and the school were strained. Hence, even though both sets of parents were involved in the education of their children, their transition parenting styles (advocates or protectors), the involvement of their adolescents in the process, and the presence or absence teacher support appeared to influence the outcomes.

The parents of Darth, Laura, and Mary may also be described as advocates during the transition process (Lindstrom et al., 2007) to postsecondary education, and their 
activities were comparable to those undertaken by Vincent's parents. At least one parent in each of these families had attended university and held a professional position, and they had similar expectations for their children (Blustein et al., 2002). Equally important, a diagnosis of LDs was not considered a barrier to achieving this goal. In two of the three cases, the mothers had modelled advocacy for their children with LDs, and their children were among the relative few who were able to learn self-advocacy without formal instruction (Michaels, 1994). Moreover, the parents and their adolescents developed positive relations with the school, and teachers were available to offer additional support during high school.

In this study, therefore, parents whose transition activities could be described as advocacy, whether their children were transitioning to employment (Lindstrom et al., 2007) or postsecondary studies, were found to be linked to positive outcomes (i.e., employment or acceptance to a university program). For adolescents whose goal was to attend university, the job status of the parents was linked to their children's postsecondary aspirations (Blustein et al., 2002); but in Vincent's case the parents' nonprofessional careers were not a barrier to career planning and exploration because a teacher stepped in to fill this gap.

\section{Roles of Adolescents with LDs}

This section analyzes findings about adolescent factors affecting the transition process, including the nature and extent of self-advocacy and self-determination. All of the adolescents accepted their LDs (Durlak et al., 1994), and two of them reframed their LDs as a positive occurrence. Darth linked his LDs to his creativity, and Mary attributed to her LDs the development of her strong work ethic and determination (Higgins, et al., 2002). Like their parents, four of the adolescents did not view LDs as a reason to refrain from achieving their post-school goals or expecting academic success in high school.

Self-advocacy and self-determination. The development of self-advocacy and selfdetermination skills is viewed as an important factor in achieving post-school transition goals (Durlak, et al., 1994). In contrast to previous research, four of the five adolescents and young adults developed self-advocacy skills, despite having received no advocacy training in high school (Michaels, 1994). Over the years, they had observed their parents advocating on their behalf and were able to implement the lessons they learned. They were also aware of their learning strengths and needs, attended the meetings to discuss the accommodations to be written on their IEPs, knew their rights, and were able to communicate their needs to others (Banks, 2014; Durlak, et al., 1994; Merchant \& Gajar, 1997; Walker \& Test, 2011).

As they progressed through high school, the adolescents also accepted responsibility for directing activities leading toward their chosen transition goals (Ward, 1988). Specifically, Vincent ensured that he took a range of technical courses and maintained part-time employment to develop work-related skills. Darth, Laura, and Mary researched university programs, monitored their progress toward their goals, and advocated for their own needs. As well, they all maintained positive relations with at least one teacher who was instrumental in helping them achieve their goals. It should also be noted that when faced with lower level course expectations by a teacher (Whitley, Lupart, \& Beran, 2007), 
Mary advocated for her postsecondary goal to attend university. She used self-advocacy to protect herself against people who view individuals with LDs as unsuited for the academic demands of postsecondary studies (Egly, 1987). Hence in this study, developing selfdetermination and taking responsibility for self-advocacy during high school were related to successful achievement of transition goals by the individuals with LDs.

The progression from being dependent on others to arrange services at school to taking control of one's behaviour to achieve a desired goal is linked to self-determination (Wehmeyer \& Mithaug, 2006). For Vincent, Darth, Laura, and Mary the overall goal of employment or acceptance into a university program was set by their parents. They were given the freedom to select a particular career and area of study of their choice, which likely supported their commitment to it. However, they all had LDs, a challenge that served as a catalyst for them to work hard to achieve their goals. According to the Causal Agency Theory (Wehmeyer \& Mithaug, 2006), they had become causal agents who were working to reach their valued goals and in the process became more self-determined. They made decisions about how to reach their goals (e.g., high school course selection) and monitored their academic progress to ensure they could achieve their specific transition goal (Zhang et al., 2002). As a result of their actions, these four students with LDs experienced success and their self-determination increased (Wehmeyer \& Mithaug, 2006).

In this research, self-determination was a condition that supported self-advocacy (e.g., attending meetings, requesting accommodations) that was thrust upon them by their LDs and by their parents' gradual withdrawal from advocating on their behalf. Selfdetermination stemmed from their parents' expectations of (a) employment or postsecondary education and (b) independence. The challenges they faced and the success they experienced through their own goal-directed actions galvanized their determination to work hard and succeed. It should also be noted that self-determination occurred within a context in which these four participants were confident that they could call upon their parents and at least one teacher at the school for support.

Alice was the only participant with LDs who did not develop self-determination or self-advocacy skills during her high school years. Audrey and Oliver did not expect their daughter to transition to employment or postsecondary studies, nor did they expect her to achieve independence. Alice did not select a career and had no goal, other than high school graduation, to work toward. It is not clear that she was even focussed on that objective, as Audrey revealed that if given the choice, Alice would have dropped out of school in Grade 4. Hence, it is possible that Alice wasn't strongly committed to that academic goal and that her LDs, instead of being a challenge to overcome, became a reason to permit Audrey continue to advocate at school and complete her daughter's assignments. Instead of developing learned hopefulness (Zimmerman \& Rappaport, 1988), she was mired in learned helplessness.

In summary, the participants with LDs had several responsibilities. They had to develop self-determination and self-advocacy skills, which combined with their own hard work led to successful academic achievement. The adolescents with LDs also had to connect with a teacher who could help them obtain resources controlled by the school. Finally, they had to know the requirements needed to achieve their transition goals in order to evaluate the advice given by some teachers. It was therefore within the context of 
the supportive relationships with their parents and teachers that the four individuals with LDs had either met their transition goals or were on track to do so.

\section{Role of Teachers}

Four participants garnered the support of at least one high school teacher who provided mentoring or assistance. One of Vincent's technical teachers helped him select a career and found a co-operative education placement that led to a part-time job and an apprenticeship, a finding consistent with results reported by Benz et al., (2000). He also served as a mentor to Vincent (for a similar finding, see Izzo \& Lamb, 2002) and collaborated with the parents to help Vincent achieve his transition goals. Laura and Mary both worked with the resource teacher in their respective high schools, who spoke to their colleagues about the girls' needs for accommodations in order to pass their courses. Darth partnered with a guidance counsellor to help him ensure that he had all the prerequisites for the film studies program to which he applied. Caring and supportive teachers, therefore, provided assistance to these four students with LDs as they strove to achieve their transition goals, even when the parents were not removed.

Alice was not on the same path as the other four adolescents with LDs. Similar to previous research (Mishna et al., 2011; Zhang, 2001), she was content to rely on her mother to advocate for her and was not expected to take full responsibility for the immediate goal of completing high school. While Alice's teachers wanted her to develop self-determination and self-advocacy, this goal was not in line with the expectations of her parents. Moreover, Alice did not develop the same type of relationship with her teachers as the other four adolescents and did not benefit from the mentoring and support that might have been provided. Alice and her teachers, therefore, appeared to play a minimal role in her transition process; instead, Audrey controlled and managed it on her own.

\section{Limitations}

Several limitations of the study must be recognized. The families in this research self-selected to participate, and they seemed motivated to tell their stories during the three interviews. However, given that the literature shows a lower success rate in employment and postsecondary education for students with LDs (Blackorby \& Wagner, 1996), it is possible that the experiences of four of the families may not be typical of most adolescents with LDs. Still, there are lessons that can be learned from their stories about the transition process among adolescents with LDs. Another limitation is that the participants chose what to reveal during the interviews. It is possible that only actions resulting in positive outcomes were shared. Additionally, no data from the adolescents' teachers were collected, and therefore this study lacks the perspective of the schools.

\section{Conclusions}

In this study, the transition process from high school to employment or postsecondary studies was examined from the perspectives of five individuals with LDs and their parents. The unique contribution of this research is a description of how the process unfolded during the high school years and of the interactions of the stakeholders. 
The findings reveal that the transition process was informed by the diagnosis and an understanding of the strengths and needs of the adolescents with LDs. As well, the process appeared to occur in two phases, with the first phase taking place during the elementary and early secondary school years. In this period the parents initiated and drove the transition process; their children with LDs were willing participants in the process, and teachers provided support for the adolescents. Specifically, the parents expressed the goals of employment or postsecondary education for their children with LDs, with the understanding that they would eventually live independently. The parents also advocated for accommodations to be listed on the IEP, and they modelled educational advocacy skills. During this phase the adolescents decided on particular careers that were aligned with their parents' expectations, worked hard, and began to develop self-determination and self-advocacy skills. Teachers supported the adolescents by providing accommodations when necessary.

The second phase began in the middle and final high school years and was characterized by the transfer of the responsibility for the transition process from the parents to their children. In this period the students with LDs learned that despite the challenge of their disability, their own efforts could produce positive results at school. They developed self-determination, perceived themselves as capable, and, with the help of a teacher, managed their academic studies so as to realize their transition goals. In turn, the parents progressively gave them more advocacy responsibilities, and the students honed their self-advocacy skills. By the end of high school the adolescents were managing the transition process, calling on support from parents or teachers as required. During the second phase, therefore, the roles of the parents and adolescents with LDs also underwent a transition. Responsibility for controlling the transition process and advocacy for accommodations shifted from the parents to the adolescents with LDs, and the parents gradually began playing a supportive role along with the teachers. Though not as significant as the relationship with their parents, their relationship with teachers was important in helping the adolescents obtain the information, opportunities, and support they required to advance toward achieving their goals. Therefore, the findings point to a two-phased process involving collaboration and interaction among the three stakeholders. While the school provided assistance and mentorship for the adolescent with LDs throughout the transition process, the roles and interactions of the parents and children changed over time.

Four of the five families participating in this research experienced this pattern of interaction, which led to a successful transition experience-the child with LDs was either heading toward acceptance by a university or had already reached the goal of employment or postsecondary studies. These were success stories. In one family, though, the transition process was never fully embraced by the parents, the adolescent with LDs, or the school. While the factor of parental involvement was in place, parental expectations for independence, employment, or further education were lacking. As well, the adolescent did not develop self-determination and self-advocacy, and support from the school was absent. As shown in this study, the transition process is complex, and mobilizing all these factors may be more difficult to achieve than illustrated by the other four cases in this research, which may contribute to the poor post-school outcomes of 
students with LDs reported in the literature (Newman, Wagner, Cameto, Knokey, \& Shaver, 2010; Wagner et al., 2005).

One factor related to positive outcomes was having a transition plan. In this study none of the families had a formal document outlining transition goals and steps to reach them. Instead, four families were proactive in developing their own informal plans that took shape as the adolescents progressed through high school and involved the collaboration of the parents, the adolescent with LDs, and a teacher who provided appropriate assistance to the student (e.g., useful advice, co-operative education placements, organizational assistance, and assistance obtaining accommodations). What seemed to be important for these students with LDs was having a shared understanding about post-school goals and how to reach them with their parents and teachers.

Perhaps formal transition plans are more important when the adolescent's need, interests, and preferences require community involvement in the transition planning, such as supportive employment experiences. Formal transition plans may also be critical for adolescents with LDs whose parents are considered to be removed. As shown by Lindstrom et al. (2007), teachers who were transition specialists worked with students with LDs to provide advocacy and career-related activities in the absence of their families. An implication for high schools is to provide transition services that involve goal setting, the development of self-determination and self-advocacy skills, and careerrelated activities for adolescents with LDs, particularly when their parents are not strong advocates or when post-school goals are vague.

Another finding is the important role that teachers can undertake in the transition process by helping students with LDs develop self-determination and self-advocacy skills (also see Zhang et al., 2002). Moreover, an informed and caring teacher can propel an adolescent's transition plans, even when the parents are actively involved. Beginning in the intermediate grades, teachers should initiate the discussion about transition goals with the parents and their children with LDs during the annual IEP meetings. As shown in this study and in previous research (Blustein et al., 2002; Lindstrom et al., 2007), parental expectations were adopted by their children and provided a direction for the high school years. Teachers should be vigilant when, as in Alice's case, the parents have not identified employment or postsecondary goals for their adolescent. They should also try to collaborate with the parents to help the student with LDs take ownership of their transition goals and achieve them.

Although the adolescents with LDs in this research developed self-advocacy skills without formal instruction, high school resource teachers should undertake the task of teaching these skills to adolescents with LDs and require that they be practised during IEP meetings and when requesting accommodations. Several self-advocacy programs are available for use in schools, such as the IPARS strategy (VanReusen \& Bos, 1994) and the SHARE technique combined with IPLAN (Lancaster, Schumaker, \& Deshler, 2002; Van Reusen, Deshler, \& Schumaker, 1989). Knowledge of their strengths and needs and well-developed self-advocacy skills will likely be helpful in post-secondary studies.

The findings of this research demonstrated that parents' high expectations regarding a transition goal and support of their adolescent in achieving it are linked to the development of self-determination and self-advocacy skills. As well, an advocate 
parenting style during the transition process that included giving their adolescents with LDs increasingly more responsibility for managing the process may also have contributed to the development of self-determination and self-advocacy among their children. While having a plan is important, in this study it was also found that in the absence of a formal transition plan, an informal one was sufficient to identify goals and provide direction to the process. Another important finding was that although parents, adolescents with LDs, and teachers had distinctive roles in the transition process, positive results occurred when they collaborated. Further research is needed to examine the nature of this collaboration, particularly how students with LDs may be supported in accepting increased responsibility for the transition process during high school. As teachers were not interviewed in this research, further investigation on the nature of their role in mentoring and supporting students during transition to employment or postsecondary studies is warranted. Studies involving students with LDs whose parents are not active in the transition process should also be undertaken. Given the negative statistics presented in the literature about post-school outcomes of individuals with LDs (Murray, et al., 2000; Wagner, Newman, Cameto, Levine, \& Garza, 2006), it may often be the case that adolescents with LDs do not have high school and postsecondary transition goals or adults who are committed to helping them achieve them. Additional research could provide much-needed information regarding how parents and educators can work together to improve the likelihood of successful transitions for students with LDs.

\section{References}

Abery, B., \& Stancliffe, R. (1996). The ecology of self-determination. In D. J. Sands \& M. Wehmeyer (Eds.), Self-determination across the life span: Independence and choice for people with disabilities (pp. 111-145). Baltimore, MD: Paul Brookes.

Baer, R., Flexer, R., Beck, S., Amstutz, N., Hoffman, L., Brothers, J., Stelzer, D., \& Zechman, C. (2003). A collaborative follow-up study on transition service utilization and post-school outcomes. Career Development for Exceptional Individuals, 26, 7-25. doi:1177/088572880302600102

Banks, J. (2014). Barriers and supports to postsecondary transition: Case studies of African American students with disabilities. Remedial and Special Education, 35, 28-39. doi: $10.1177 / 0741932513512209$

Beale, A. (2005). Preparing students with learning disabilities for postsecondary education: Their rights and responsibilities. Techniques, 80, 24-27.

Benz, M., Lindstrom, L., \& Yovanoff, P. (2000). Improving graduation and employment outcomes of students with disabilities: Predictive factors and student perspectives. Exceptional Children, $66,509-529$.

Blackorby, J., \& Wagner, M. (1996). Longitudinal postschool outcomes of youth with disabilities: Findings from the national longitudinal transition study. Exceptional Children, 62, 399-413.

Blustein, D., Chaves, A., Diemer, M., Gallagher, L., Marshall, K., Sirin, S., \& Kuldhir, B. (2002). Voices of the forgotten half: The role of social class in the school-to-work transition. Journal of Counseling Psychology, 49, 311-323. doi:10.1037//0022-0167.49.3.311

Briel, L., \& Getzel, E. (2001). Internships in higher education: Promoting success for students with disabilities. Disability Studies Quarterly, 21, 38-48. 
Charmaz, K. (2000). Grounded theory objectivist and constructivist methods. In N. K. Denzin \& Y. S. Lincoln (Eds.), Handbook of qualitative research (2nd ed., pp. 509-536). Thousand Oaks, CA: Sage.

Creswell, J. (2009). Research design: Qualitative, quantitative, and mixed methods approaches (3rd ed.). Los Angeles, CA: Sage.

Duquette, C., Stodel, E., Fullarton, S., \& Hagglund, K. (2012). Adolescents with fetal alcohol spectrum disorder and parent advocacy in education. International Journal of Inclusive Education, 16, 1203-1221. doi:10.1080/13603116.2011.557445

Durlak, C., Rose, E., \& Bursuck, W. (1994). Preparing high school students with learning disabilities for the transition to postsecondary education: Teaching the skills of self-determination. Journal of Learning Disabilities, 27, 51-59.

Egly, N. (1987). Self-advocacy and assertiveness for the disabled college student and how to use selfadvocacy skills. ERIC Document Reproduction Service No. ED 286 311. University of Nebraska, Lincoln.

Field, S., Sarver, M., \& Shaw, S. (2003). Self-determination: A key to success in postsecondary education for students with learning disabilities. Remedial and Special Education, 24, 339349. doi:10.1177/07119325030240060501

Fullarton, S. (2006, May). Postsecondary school outcomes for students with learning disabilities. Paper presented at the 75th Congress of the Humanities and Social Sciences, Toronto, ON.

Higgins, E., Raskind, M., Goldberg, R., \& Herman, K. (2002). Stages of acceptance of a learning disability: The impact of labeling. Learning Disability Quarterly, 25, 3-18. doi: $10.2307 / 1511187$

Izzo, M., \& Lamb, P. (2002). Self-determination and career development: Skills for successful transition to postsecondary education and employment. Unpublished manuscript. Retrieved from http://www.rrtc.hawaii.edu/documents/products/phase2/pdf/062d\%281\%29-H01.pdf

Kohler, P. D. (1993). Best practices in transition: Substantiated or implied? Career Development for Exceptional Individuals, 16, 107-121.

Kotzer, E., \& Margalit, M. (2007). Perception of competence: Risk and protective predictors following an e-self-advocacy intervention for adolescents with learning disabilities. European Journal of Special Needs Education, 22, 443-457. doi:10.1080/08856250701650060

Kurth, N., \& Mellard, D. (2006). Student perceptions of the accommodations process in postsecondary education. Journal of Postsecondary Education and Disability, 19, 69-82.

Lancaster, P., Schumaker, J., \& Deshler, D. (2002). The development and validation of an interactive hypermedia program for teaching a self-advocacy strategy to students with disabilities. Learning Disability Quarterly, 25, 443-457. doi:10.2307/1511358

Lincoln, Y. S., \& Guba, E. G. (1985). Naturalistic inquiry. Beverly Hills, CA: Sage.

Litner, B., Mann-Feder, V., \& Guérard, G. (2005). Narratives of success: Learning disabled students in university. Exceptionality Education Canada, 15(1), 9-24.

Mellard, D., \& Johnson, P. (2007). RTI: A practitioner's guide to implementing response to intervention. Thousand Oaks, CA: Corwin Press.

Mellard, D., \& Lancaster, P. (2003). Incorporating adult community services in students' transition planning. Remedial and Special Education, 25, 24-31.

Merchant, D., \& Gajar, A. (1997). A review of the literature on self-advocacy components in transition programs for students with learning disabilities. Journal of Vocational Rehabilitation, 8, 223-231. 
Merriam, S. (1998). Qualitative research and case study applications in education. San Francisco, CA: Jossey-Bass Publishers.

Mertens, D. (2005). Research and evaluation in education and psychology (2nd ed.). Thousand Oaks, CA: Sage.

Michaels, C. (1994). Transition strategies for persons with learning disabilities. San Diego, CA: Singular Publishing Group, Inc.

Miles, M. B., \& Huberman, A. M. (1994). Qualitative data analysis: An expanded sourcebook. Thousand Oaks, CA: Sage.

Milsom, A. (2002). Students with disabilities: School counselor involvement and preparation. Professional School Counseling, 5, 331- 338.

Ministry of Education. (2002). Transition planning: A resource guide. Toronto, ON: Ministry of Education.

Mishna, F., Muskrat, B., Farnia, F., \& Weiner, J. (2011). The effects of a school-based program on the reported self-advocacy knowledge of students with learning disabilities. Alberta Journal of Educational Research, 57, 185-203.

Murray, C., Flannery, B., \& Wren, C. (2008). University staff members' attitudes and knowledge about learning disabilities and disability support services. Journal of Postsecondary Education and Disability, 21, 73-90.

Murray, C., Goldstein, D., Nourse, S., \& Edgar, E. (2000). The postsecondary school attendance and completion rates of high school graduates with learning disabilities. Learning Disabilities Quarterly, 15, 119-127. doi:10.1207/SLDRP1503_1

Newman, L., Wagner, M., Cameto, R., \& Knokey, A. (2009). The post-high school outcomes of youth with disabilities up to 4 years after high school. A report of findings from the National Longitudinal Transition Study-2 (NLTS2) (NCSER 2009-3017). Menlo Park, CA: SRI International. Retrieved from www.nlts2.org/reports/2009_04/nlts2_report_2009_04_complete.pdf

Newman, L., Wagner, M., Cameto, R., Knokey, A. M., \& Shaver, D. (2010). Comparisons across time of the outcomes of youth with disabilities up to 4 years after high school. A report of findings from the National Longitudinal Transition Study-2 (NLTS2). Menlo Park, CA: SRI International. Retrieved from www.nlts2.org/reports/2010_09/nlts2_report_2010_09_complete.pdf

Nichols, E., Paul, C., Vandenbossche, D., Yaworski C., \& Ziraldo, L. (2003). Transition planning resource guide for students with learning disabilities. Revised from a document developed for LDAO in May 1999 by: Learning Disabilities Association of Ontario. Retrieved from http://www.access.resources.ldao.ca/main/documents/TransitionPlanningResourceGuide4.pdf

Ontario Ministry of Community and Social Services. (2012). Ontario disability support programs: Employment support. Toronto: Queen's Printer for Ontario. Retrieved from http://www.mcss.gov.on.ca/en/mcss/programs/social/odsp/employment_support/appeal.aspx

Phillips, P. (2001). A self-advocacy plan for high school students with learning disabilities: A comparative case study analysis of students', teachers', and parents' perceptions of program effects. Journal of Learning Disabilities, 23, 466-471.

Pocock, A., Lambros, S., Karvonen, M., Test, D., Algozzine, B., Wood, W., \& Martin, J. (2002). Successful strategies for promoting self-advocacy among students with LD: The LEAD group. Intervention in School and Clinic, 37, 209-216. doi:10:1177/105345120203700403

Prater, M., Redman, A., Anderson, D., \& Gibb, G. (2014). Teaching adolescent students with learning disabilities to self-advocate for accommodations. Intervention in School and Clinic, 49, 298305. doi:10.1177/10534512135113958 
Reis, S., Neu, T., \& McGuire, J. (1997). Case studies of high-ability students with learning disabilities who have achieved. Exceptional Children, 63, 463-479.

Repetto, J., Webb, K., Neubert, D., \& Curran, C. (2006). The middle school experience: Successful teaching and transition for diverse learners. Austin, TX: Pro-Ed.

Ryan, R. M., \& Deci, E. L. (2000). When rewards compete with nature: The undermining of intrinsic motivation and self-regulation. In C. Sansone \& J. M. Harackiewicz (Eds.), Intrinsic and extrinsic motivation: The search for optimal motivation and performance (pp. 13-54). New York, NY: Academic Press.

Seidman, I. (2006). Interviewing as qualitative research (3rd ed.). New York, NY: Teachers College Press.

Sowers, J., \& Smith, M. (2003). A field-test of the impact of an in-service training program on health sciences educational faculty. Journal Postsecondary Education and Disability, 17, 33-48.

Stake, R. (1995). The art of case study research. Thousand Oaks, CA: Sage.

Trainor, A. (2008). Using cultural and social capital to improve postsecondary outcomes and expand transition models for youth with disabilities. The Journal of Special Education, 42, 148-162. doi: $10.1177 / 0022466907313346$

Traustadottir, R. (1991). Mothers who care gender, disability, and family life. Journal of Family Issues, 12, 211-228.

Van Reusen, A., \& Bos, C. (1994). Facilitating student participation in individualized education programs through motivation strategy instruction. Exceptional Children, 60, 466-475.

Van Reusen, A., Deshler, D., \& Schumaker, J. (1989). Effects of a student participation strategy in facilitating the involvement of adolescents with learning disabilities in the individualized educational program planning process. Learning Disabilities, 1, 23-34.

Vogel, S., \& Adelman, P. (1993). Success for college students with learning disabilities. New York, NY: Springer.

Wagner, M., Newman, L., Cameto, R., Garza, N., \& Levine, P. (2005). After high school: A first look at the postschool experiences of youth with disabilities. A report from the National Longitudinal Transition Study-2 (NLTS2). Menlo Park, CA: SRI International. Retrieved from www.nlts2.org/reports/2005_04/nlts2_report_2005_04_complete.pdf

Wagner, M., Newman, L., Cameto, R., Levine, P., \& Garza, N. (2006). An overview of findings from wave 2 of the National Longitudinal Transition Study-2 (NLTS2). A report from the National Longitudinal Transition Study-2 (NLTS2). Menlo Park, CA: SRI International. Retrieved from www.nlts2.org/reports/2006_08/nlts2_report_2006_08_complete.pdf

Walker, A., \& Test, D. (2011). Using a self-advocacy intervention on African-American college students' ability to request academic accommodations. Learning Disabilities Research \& Practice, 26, 134-144. doi:10.1111/j.1540-5826.2011.0333.x

Ward, M. (1988). The many facets of self-determination. NICHCY transition summary. National Center for Children and Youth with Disabilities, 5, 2-3.

Wehmeyer, M., \& Mithaug, D. (2006). Self-determination, causal agency, and mental retardation. International Review of Research in Mental Retardation, 31, 31-71. doi:10.1016/S00747750(05)31002-0

Whitley, J., Lupart, J., \& Beran, T. (2007). The characteristics and experiences of Canadian students receiving special education services for a learning disability. Exceptionality Education Canada, 17, 85-109. 
Zhang, D. (2001). The effect of NEXT S.T.E.P. instruction on the self-determination skills of high school students with learning disabilities. Career Development for Exceptional Individuals, 24, 121-132. doi:1177/088572880102400203

Zhang, D., Katsiyannis, A., Zhang, J. (2002). Teacher and parent practice on forstering selfdetermination of high school students with mild disabilities. Career Development for Exceptional Individuals, 25, 157-169. doi:10.1177/088572880202500205

Zimmerman, M., \& Rappaport, J. (1988). Citizen participation, perceived control, and psychological empowerment. American Journal of Community Psychology, 16, 725-750.

\section{Authors' Note}

Correspondence concerning this article should be addressed to Cheryll Duquette, Faculty of Education, University of Ottawa, Ottawa, ON, K1N 6N5, Canada. E-mail: cduquett@uottawa.ca 